\title{
Influência da Fitase na Utilização de Nutrientes em Dietas Compostas por Milho e Farelo de Soja para Suínos em Crescimento ${ }^{1}$
}

\author{
Maria do Carmo Mohaupt Marques Lüdke², Jorge López ${ }^{3}$, Paulo Antônio Rabenschlag de Brum4, \\ Jorge Vitor Lüdke 4
}

RESUMO - O objetivo deste trabalho foi determinar o nível adequado de fitase (0,300, 600 e $900 \mathrm{UF} / \mathrm{kg}$ da dieta) a ser adicionado em dietas contendo milho e farelo de soja com dois níveis de proteína bruta (PB), um na exigência do animal (18\%)e outro em nível menor (16\%), para a mais efetiva biodisponibilidade do nitrogênio, da energia e dos macrominerais, e também verificar em qual destes níveis de proteína da dieta a fitase tem maior efeito. Foram utilizados 24 leitões com peso médio inicial de 18,4 kg, alojados em gaiolas metabólicas, para ensaio de metabolismo do nitrogênio, da energia bruta, do fósforo e cálcio, por intermédio do método com marcador óxido férrico. As dietas foram fornecidas de acordo com o peso metabólico dos animais e foram isoenergéticas com $3295 \mathrm{kcal}$ de EM/kg. Foram avaliados os parâmetros de desempenho dos animais, a digestibilidade do nitrogênio (DN), a retenção de nitrogênio (RN), a energia digestível (ED), a energia metabolizável (EM), a digestibilidade do fósforo (DP), a retenção do fósforo (RP), a digestibilidade do cálcio (DCa) e a retenção do cálcio (RCa). Foi observado aumento na biodisponibilidade dos nutrientes, ao ser adicionada fitase nos níveis entre 220 e 508 UF/kg da dieta, exceto no desempenho dos animais, que aumentou linearmente. A eficiência da enzima foi melhor, quando adicionada em dietas contendo nível de proteína marginal (16\% de PB) comparado às dietas com 18\% de proteína bruta, ao avaliar a energia.

Palavras-chave: digestibilidade, energia, enzima, fitato, metabolismo

\section{Influence of the Phytase in the Use of Nutrients in Diets Compound by Corn-Soybean Meal for Growing Pigs}

\begin{abstract}
The objective of this trial was to determine the adequate level of the phytase $(0,300,600$ and $900 \mathrm{PU} / \mathrm{kg}$ of the diet) to be added in corn-soybean meal diets with two crude protein $(\mathrm{CP})$ levels, one at the animal requirements $(18 \% \mathrm{CP})$ and another at smaller level $(16 \% \mathrm{CP})$, for the most effective nitrogen bioavailability, of the energy and of the macro minerals, and also to observe in which of these diet protein levels the phytase has larger effect. Twenty-four pigs with initial weight of $18,4 \mathrm{~kg}$ were housed in metabolic cages for metabolism assay of the nitrogen, gross energy, phosphorus and calcium, through the method using ferric oxide as a marker. The diets were supplied in accordance to the animal's metabolic weight, and they were isoenergetic with $3295 \mathrm{kcal}$ of ME/ $\mathrm{kg}$. The animal performance traits, the nitrogen digestibility (ND), nitrogen retention (NR), digestive energy (DE), metabolizable energy (ME), phosphorus digestibility (PD), phosphorus retention (PR), calcium digestibility $(\mathrm{CaD})$ and calcium retention $(\mathrm{CaR})$ were evaluated. An increase in the nutrient bioavailabilities were observed to the added phytase in the levels from $220-508 \mathrm{UF} / \mathrm{kg}$ of the diet, except in the animal's performances that increased linearly. When energy was evaluated, the enzyme efficiency was better when it was added in marginal protein diet levels, $16 \% \mathrm{CP}$, as compared with diets of $18 \% \mathrm{CP}$.
\end{abstract}

Key Words: digestibility, energy, enzyme, metabolism, phytate

\section{Introdução}

Para ter desenvolvimento normal, as plantas retiram seus nutrientes minerais do solo, sendo que na fase de maturação do grão há translocação destes elementos para sementes e, no caso do fósforo, na forma de ácido fítico (JONGBLOED, 1987). De acordo com LEHNINGER (1993), o fitato ou fósforo fítico é a designação dada ao fósforo, que faz parte da molécula do ácido fítico (hexa-fosfato de inositol) encontrado nos vegetais. Por causa do seu grupo ortofosfato, altamente ionizado, este complexa com uma variedade de cátions $(\mathrm{Ca}, \mathrm{Fe}, \mathrm{Cu}, \mathrm{Zn}$, entre outros), o grupo amina de alguns aminoácidos (lisina, arginina, histidina) e, ainda, moléculas conjugadas de glicose, especialmente no amido. Este complexo

\footnotetext{
${ }^{1}$ Parte da Tese de Doutorado apresentada pelo primeiro autor à Faculdade de Agronomia da UFRGS, como um dos requisitos para obtenção do Grau de Doutor em Zootecnia.

2 Zootecnista, Dra . Nutrição Animal. Bolsista Recém-Doutor do CNPq. E.mail: jmcludke@matrix.com.br

3 Professor Titular do Departamento de Zootecnia da Faculdade de Agronomia da UFRGS.

4 Pesquisadores de Nutrição da EMBRAPA - CNPSA. E.mail: pbrum@cnpsa.embrapa.br; jorge@cnpsa.embrapa.br
} 
categoriza o fitato como um fator antinutricional, por diminuir a disponibilidade de minerais, além de proteínas e energia (MORRIS, 1986). De maneira geral, de acordo com o NATIONAL RESEARCH COUNCIL - NRC (1998), a disponibilidade biológica do fósforo de origem vegetal para suínos varia entre 15 e $50 \%$ em grãos. No milho, a disponibilidade do fósforo é muito baixa, variando de 9 a $18 \%$ (CROMWELL, 1990). Na soja, além da indisponibilidade do fósforo, o fitato está associado às proteínas, pois, segundo O'DELLe DeBOLAND (1976), as frações protéicas da soja se ligam fortemente ao fitato, o que não ocorre com as proteínas do germe do milho. Devido a este fator antinutricional nos alimentos de origem vegetal para os não-ruminantes, as fezes excretadas por estes animais apresentam altos teores de fósforo fítico e, também, nitrogênio, pois estes nutrientes presentes na molécula do fitato, somado à fonte inorgânica (fósforo) e ao aumento do nível de proteína na ração acima da exigência do animal, serão excretados. O fosfato e o nitrogênio presentes em excesso no solo acarretam problemas sérios para o meio ambiente, por intermédio do processo chamado eutroficação, para o fósforo, e nitrificação, para o nitrogênio. Ambos ocasionam diminuição da quantidade de oxigênio existentes nas águas dos rios e lagos, criando, assim, um meio inadequado para os peixes e outros animais aquáticos (CROMWELL, 1992).

É possível reduzir o potencial poluente dos dejetos de suínos mediante a adoção de técnicas alimentares mais equilibradas. Como exemplo, a excreção do nitrogênio é reduzida diminuindo o conteúdo de proteína da dieta e suplementando com aminoácidos, ou ainda, utilizar um manejo nutricional, utilizando dietas diferenciadas, por fase do animal e por sexo, e a enzima fitase (STILLBORN, 1998). Esta enzima é produzida industrialmente pelos fungos Aspergillus niger e Aspergillus ficuum, por intermédio de técnicas de recombinação de DNA. O potencial da enzima é influenciado pelo nível da dieta de fósforo total e disponível (incluindo fósforo fítico), pela quantidade de fitase suplementada, pelo nível de vitamina $D$ e pela relação cálcio e fósforo (KORNEGAY, 1996).

Pelo exposto acima, o objetivo deste trabalho foi determinar o nível adequado de fitase a ser adicionado em dietas contendo milho e farelo de soja para a mais efetiva biodisponibilidade de nitrogênio, energia, fósforo e cálcio. Adicionalmente, objetivou-se verificar em que nível de proteína da dieta a fitase tem maior efeito.

\section{Material e Métodos}

O experimento foi conduzido na sala de metabolismo da granja experimental do Sistema de Produção de Suínos no Centro Nacional de Pesquisa de Suínos e Aves (CNPSA) - EMBRAPA, localizada em Concórdia - SC, Brasil, no período de 1ํㅡㄹ junho a 28 de junho de 1996. Foram utilizados 24 leitões machos castrados F2, provenientes da cruza de fêmeas F1 (Landrace x Large White) e macho sintético M558 (Pietran x Duroc x Hampshire), com pesos inicial e final médio de 18,4 e $32,3 \mathrm{~kg}$, respectivamente, alojados em gaiolas metabólicas, modelo descrito por PEKAS (1968). Foi fornecida água à vontade. Os animais foram submetidos a ensaios de digestibilidade aparente, com coletas de fezes e urina para posteriores análises laboratoriais. Foram realizados quatro períodos de coleta de fezes e urina em 16 dias (quatro dias de coleta/semana em quatro períodos), sendo cada semana considerada um período, pois os animais foram pesados semanalmente. Foi utilizado o marcador óxido férrico na ração, em concentração de $0,125 \%$, para que os animais excretassem fezes marcadas, indicando o momento de início da coleta de fezes e, dessa forma, caracterizando o início e o final de cada período de coleta. A sala de metabolismo era climatizada com temperatura em torno dos $22^{\circ} \mathrm{C}$. Foram analisadas as concentrações de matéria seca, nitrogênio, energia bruta, fósforo e cálcio nas fezes e na urina, para obtenção da digestibilidade e metabolização destes nutrientes, de acordo com o método descrito na ASSOCIATION OF OFFICIAL ANALYTICAL CHEMISTS - AOAC (1984). No entanto, a determinação de fósforo e cálcio na urina foi realizada segundo o método do LABTEST (1985) e LABTEST (1996), respectivamente, por existirem dois kits em amostras de sangue ou urina para humanos e animais. Também foram avaliados o desempenho dos animais, o consumo da dieta, o ganho de peso e a conversão alimentar, durante o ensaio de metabolismo.

As dietas foram fornecidas de acordo com o peso metabólico (PM) do animal. O cálculo foi baseado na premissa de que a exigência de energia para mantença do animal é de $110 \mathrm{kcal}$ de EM/kg/d (NATIONAL RESEARCH COUNCIL - NRC, 1988), que, ao multiplicar pelo peso metabólico do animal por 3 , resulta na quantidade de EM fornecida. Ao dividir esta EM pela EM da dieta, foi encontrada a quantidade de dieta fornecida em relação ao PM do animal, o qual foi calculado utilizando o peso inicial do período somado ao peso estimado para o final do mesmo 
1404 Rev. bras. zootec.

período, dividido por 2 e elevado ao expoente 0,75 . Estas dietas foram isoenergéticas com $3295 \mathrm{kcal}$ de $\mathrm{EM} / \mathrm{kg}$, mas com dois níveis de proteína bruta (PB), $18 \%$ (NRC, 1988) e 16\% (abaixo da exigência do animal com este peso), e quatro níveis de fitase: 0 , 300, 600 e 900 UF (Unidades de Fitase)/kg da dieta. Com isso, os tratamentos foram organizados da seguinte forma:

Dietas com 18\% de PB: (1) DB (Dieta basal) $=$ (Milho + farelo de soja + óleo de soja + premix mineral e vitamínico, + aditivos + calcáreo) + fosfato bicálcico $(\mathrm{FB})(1,41 \mathrm{~kg} / 100 \mathrm{~kg}$ da dieta $)+0 \mathrm{UF} / \mathrm{kg}$; (2) $\mathrm{DB}+\mathrm{FB}(1,02 \mathrm{~kg} / 100 \mathrm{~kg}$ da dieta $)+300 \mathrm{UF} / \mathrm{kg}$; (3) $\mathrm{DB}+\mathrm{FB}(0,63 \mathrm{~kg} / 100 \mathrm{~kg}$ da dieta $)+600 \mathrm{UF} / \mathrm{kg}$; $\mathrm{e}(4) \mathrm{DB}+\mathrm{FB}(0,23 \mathrm{~kg} / 100 \mathrm{~kg}$ da dieta $)+900 \mathrm{UF} / \mathrm{kg}$. As dietas com $16 \%$ de $\mathrm{PB}$ foram semelhantes às com $18 \%$ de $\mathrm{PB}$, porém com nível maior de milho e menor de farelo de soja, sendo os níveis de FB de (5) 1,37 kg/ $100 \mathrm{~kg}$ da dieta; (6) $0,98 \mathrm{~kg} / 100 \mathrm{~kg}$ da dieta; (7) $0,59 \mathrm{~kg} / 100 \mathrm{~kg}$ da dieta e (8) $0,20 \mathrm{~kg} / 100 \mathrm{~kg}$ da dieta, para as respectivas dietas suplementadas com fitase. A composição dos ingredientes usados nas dietas pode ser observada na Tabela 1 e a composição das dietas com a respectiva análise químico-bromatológica ou calculada, na Tabela 2.

Ao ser adicionada a fitase na dieta, foi reduzida a concentração do suplemento inorgânico (fosfato bicálcico), por ter-se a recomendação da BASF S/A de que a atividade de 500 UF é equivalente a $1,15 \mathrm{~g}$ de fósforo do fosfato bicálcico; a partir daí estabeleceu-se a quantidade deste suplemento inorgânico na dieta, de acordo com a unidade de enzima utilizada. O teor de cálcio das dietas com fitase foi reduzido em $10 \%$ em relação à dieta testemunha (sem fitase e com fosfato inorgânico), ficando a mesma concentração de cálcio entre os níveis de fitase utilizados. A enzima utilizada, NATUPHOS 5.000, fornecida pela BASF, é a marca registrada da fitase obtida por intermédio da fermentação com fungos do grupo Aspergillus niger, em que uma unidade de atividade de fitase é definida pela quantidade de enzima que libera 1 micromol de fósforo em 1 minuto num substrato de sódio-fitato a $37^{\circ} \mathrm{C} \mathrm{em} \mathrm{pH} \mathrm{5,5.}$

$\mathrm{O}$ delineamento experimental foi em blocos casualizados com três blocos e oito tratamentos, consistindo em um fatorial $2 \times 4$, dois níveis de proteína bruta (18 e $16 \%)$ e quatro níveis de fitase $(0$, 300, 600 e $900 \mathrm{UF} / \mathrm{kg}$ da dieta). Cada repetição foi considerada uma unidade experimental, representada por uma gaiola metabólica com um animal, e o critério de bloqueamento foi o peso dos animais no início do experimento. Na análise de variância dos dados, adotou-se o modelo estatístico representado simbolicamente por:

em que

$$
\mathrm{y}_{\mathrm{jik}}=\mu+\mathrm{b}_{\mathrm{j}}+\mathrm{p}_{\mathrm{i}}+\mathrm{f}_{\mathrm{k}}+\mathrm{pf}_{\mathrm{ik}}+\mathrm{e}_{\mathrm{jik}}
$$

$\mathrm{Y}_{\mathrm{jik}}=$ valor observado da variável resposta pertencente à gaiola jik;

$\mathrm{j}=1,2,3$ blocos;

$\mathrm{i}=1,2$ níveis de proteína;

$\mathrm{k}=1,2,3,4$ níveis de fitase;

$\mu$ = estimativa da média geral da resposta no experimento;

$\mathrm{b}_{\mathrm{j}}=$ efeito do bloco $\mathrm{j}$;

$\mathrm{p}_{\mathrm{i}}$ = efeito do nível de proteína $\mathrm{i} ;$

Tabela 1 - Composição dos ingredientes usados nas dietas experimentais ${ }^{1}$

Table 1 - Composition of the ingredients used in the diets ${ }^{1}$

\begin{tabular}{|c|c|c|c|c|c|c|}
\hline \multirow[t]{2}{*}{$\begin{array}{l}\text { Nutriente } \\
\text { Nutrient }\end{array}$} & \multicolumn{6}{|c|}{$\begin{array}{c}\text { Ingrediente } \\
\text { Ingredient }\end{array}$} \\
\hline & $\begin{array}{r}\text { Milho } \\
\text { Corn }\end{array}$ & $\begin{array}{c}\text { Farelo de soja } \\
\text { Soybean meal }\end{array}$ & $\begin{array}{c}\text { Óleo }^{2} \\
\text { Oil }\end{array}$ & $\begin{array}{c}\text { F. bicálcico } \\
\text { Dicalcium phosphate }\end{array}$ & $\begin{array}{l}\text { Calcário } \\
\text { Limestone }\end{array}$ & $\begin{array}{l}\text { L-Lisina } \\
\text { L-Lysine }\end{array}$ \\
\hline $\mathrm{PB}(C P), \%$ & 7,92 & 46,68 & 0,00 & 0,00 & 0,00 & 94,00 \\
\hline Lisina (Lysine $), \%$ & 0,25 & 2,82 & 0,00 & 0,00 & 0,00 & 78,50 \\
\hline Metionina (Methionine), \% & 0,15 & 0,71 & 0,00 & 0,00 & 0,00 & 0,00 \\
\hline Triptofano (Tryptophan), \% & 0,06 & 1,12 & 0,00 & 0,00 & 0,00 & 0,00 \\
\hline $\operatorname{EM}(M E)(\mathrm{kcal} / \mathrm{kg})^{3}$ & 3350 & 3389 & 8135 & 0,00 & 0,00 & 0,00 \\
\hline $\mathrm{EE}(\%)$ & 3,84 & 1,40 & 100 & 0,00 & 0,00 & 0,00 \\
\hline $\mathrm{FB}(C F), \%$ & 2,17 & 5,68 & 0,00 & 0,00 & 0,00 & 0,00 \\
\hline Cálcio(Calcium), \% & 0,04 & 0,28 & 0,00 & 23,25 & 36,00 & 0,00 \\
\hline $\mathrm{P}$ total $($ Total P), \% & 0,26 & 0,61 & 0,00 & 17,60 & 0,04 & 0,00 \\
\hline $\mathrm{P}$ disponível (Available P), $\%^{3}$ & 0,08 & 0,20 & 0,00 & 17,60 & 0,04 & 0,00 \\
\hline
\end{tabular}

${ }^{1}$ Valores determinados pelo CNPSA - EMBRAPA.

2 Óleo de soja.

3 Valor tabelado segundo NRC (1988).

1 Analyzed by CNPSA - EMBRAPA.

2 Soybean oil.

3 Value according to NRC (1988). 
Tabela 2 - Composição e análise química das dietas dos animais Table 2 - Composition and chemical analysis of the diets of the animals

\begin{tabular}{|c|c|c|c|c|c|c|c|c|}
\hline \multirow{3}{*}{$\begin{array}{l}\text { Ingrediente (\%) } \\
\text { Ingredient }\end{array}$} & \multicolumn{8}{|c|}{ Tratamento (Treatment) } \\
\hline & \multicolumn{4}{|c|}{$16 \% \mathrm{~PB}(16 \% C P)$} & \multicolumn{4}{|c|}{$18 \% \mathrm{~PB}(18 \% C P)$} \\
\hline & 0 & 300 & 600 & 900 & 0 & 300 & 600 & 900 \\
\hline Milho (Corn) & 72,80 & 72,80 & 72,80 & 72,80 & 67,74 & 67,74 & 67,74 & 67,74 \\
\hline Farelo de soja (Soybean meal) & 21,51 & 21,51 & 21,51 & 21,51 & 27,02 & 27,02 & 27,02 & 27,02 \\
\hline Óleo de soja (Soybean oil) & 1,56 & 1,56 & 1,56 & 1,56 & 1,35 & 1,35 & 1,35 & 1,35 \\
\hline Fosfato bicálcico & 1,41 & 1,02 & 0,63 & 0,23 & 1,37 & 0,98 & 0,59 & 0,20 \\
\hline \multicolumn{9}{|l|}{ Dicalcium phosphate } \\
\hline Calcário(Limestone) & 0,84 & 0,91 & 1,18 & 1,45 & 0,83 & 0,89 & 1,16 & 1,43 \\
\hline L-Lisina (L-Lysine) & 0,21 & 0,21 & 0,21 & 0,21 & 0,02 & 0,02 & 0,02 & 0,02 \\
\hline Premix vitamínico $(\text { Vitamin } P)^{1}$ & 0,30 & 0,30 & 0,30 & 0,30 & 0,30 & 0,30 & 0,30 & 0,30 \\
\hline Cloreto de colina (Choline C.) & 0,22 & 0,22 & 0,22 & 0,22 & 0,22 & 0,22 & 0,22 & 0,22 \\
\hline Premix mineral (Mineral $P.)^{2}$ & 0,30 & 0,30 & 0,30 & 0,30 & 0,30 & 0,30 & 0,30 & 0,30 \\
\hline Sal (Salt) & 0,35 & 0,35 & 0,35 & 0,35 & 0,35 & 0,35 & 0,35 & 0,35 \\
\hline Aditivo e promotores (Additive) ${ }^{3}$ & 0,50 & 0,50 & 0,50 & 0,50 & 0,50 & 0,50 & 0,50 & 0,50 \\
\hline Caulim (Caulin) & 0 & 0,26 & 0,32 & 0,39 & 0 & 0,27 & 0,33 & 0,39 \\
\hline Fitase (Phytase) & 0 & 0,06 & 0,12 & 0,18 & 0 & 0,06 & 0,12 & 0,18 \\
\hline Total & 100 & 100 & 100 & 100 & 100 & 100 & 100 & 100 \\
\hline \multicolumn{9}{|l|}{ Nutrientes } \\
\hline \multicolumn{9}{|l|}{ Nutrients } \\
\hline $\mathrm{MS}(D M), \%^{4}$ & 87,12 & 87,09 & 87,01 & 87,04 & 87,05 & 86,99 & 86,98 & 87,01 \\
\hline $\mathrm{EE}, \%^{4}$ & 4,37 & 4,49 & 4,65 & 4,46 & 4,30 & 4,21 & 4,25 & 4,21 \\
\hline $\mathrm{EM}(M E)(\mathrm{kcal} / \mathrm{kg})^{5}$ & 3295 & 3295 & 3295 & 3295 & 3295 & 3295 & 3295 & 3295 \\
\hline $\mathrm{PB}(C P), \%^{4}$ & 16,32 & 16,45 & 16,30 & 16,16 & 18,57 & 18,41 & 18,08 & 18,65 \\
\hline $\mathrm{PB}(C P), \%^{5}$ & 16,00 & 16,00 & 16,00 & 16,00 & 18,00 & 18,00 & 18,00 & 18,00 \\
\hline Lisina (Lysine), $\%^{5}$ & 0,95 & 0,95 & 0,95 & 0,95 & 0,95 & 0,95 & 0,95 & 0,95 \\
\hline $\mathrm{FB}(C F), \% 4$ & 2,52 & 2,59 & 2,52 & 2,53 & 2,67 & 2,62 & 2,86 & 2,62 \\
\hline Cinzas, $\% 4$ & 4,21 & 4,33 & 3,98 & 4,10 & 4,38 & 4,31 & 4,42 & 4,33 \\
\hline Cálcio (Calcium), $\% 4$ & 0,5 & 0,57 & 0,49 & 0,56 & 0,63 & 0,50 & 0,56 & 0,54 \\
\hline Cálcio (Calcium), \% 5 & 0,70 & 0,63 & 0,63 & 0,63 & 0,70 & 0,63 & 0,63 & 0,63 \\
\hline P Total (Total P), \% 4 & 0,51 & 0,45 & 0,39 & 0,36 & 0,55 & 0,45 & 0,38 & 0,38 \\
\hline P Total (Total P), \% 5 & 0,57 & 0,50 & 0,43 & 0,36 & 0,58 & 0,51 & 0,44 & 0,38 \\
\hline $\mathrm{P}$ disponível (Availability $P) \%^{5}$ & 0,35 & 0,28 & 0,21 & 0,14 & 0,35 & 0,28 & 0,21 & 0,14 \\
\hline Relação Ca:P (Ca:P ratio $)^{4}$ & $1,1: 1$ & $1,3: 1$ & $1,3: 1$ & $1,6: 1$ & $1,1: 1$ & $1,1: 1$ & $1,5: 1$ & $1,4: 1$ \\
\hline Relação Ca:P (Ca:P ratio $)^{5}$ & $1,2: 1$ & $1,3: 1$ & $1,5: 1$ & $1,7: 1$ & $1,2: 1$ & $1,2: 1$ & $1,4: 1$ & $1,6: 1$ \\
\hline \multicolumn{9}{|c|}{ 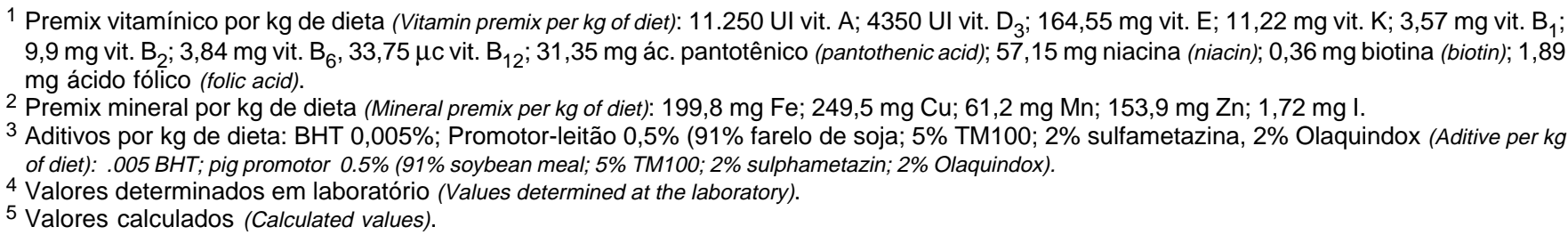 } \\
\hline
\end{tabular}

$\mathrm{f}_{\mathrm{k}} \quad=$ efeito do nível de fitase $\mathrm{k}$;

$\mathrm{pf}_{\mathrm{ik}}=$ efeito da interação resultante entre o nível de proteína i e o nível de fitase k;

$\mathrm{e}_{\mathrm{jik}}=$ erro experimental não-observado, suposto seguir a distribuição normal de probabilidade, com média zero e variância constante $\sigma^{2}$.

Adicionalmente, realizou-se o desdobramento da interação proteína $\mathrm{x}$ fitase, estudando-se os níveis de fitase dentro de cada nível de proteína. O efeito dos níveis de fitase foi desdobrado em componentes linear, quadrático, cúbico e modelo descontínuo LRP - Linear Response Plateau ou, simplesmente, linear platô, complementando-se com a estimativa de uma equação de regressão para explicar o comportamento da resposta, em função do nível de fitase usado na dieta. Segundo ANDERSON e NELSON (1975), será um modelo descontínuo LRP - Linear Response Plateau, quando houver efeitos linear e quadrático significativos. Dependendo do comportamento da resposta por inspeção gráfica e teste de significância dos contrastes testados para os efeitos, foi ajustada uma das seguintes equações de regressão: linear, $\mathrm{y}=\mathrm{a}+\mathrm{b} * \mathrm{f}$, quadrática, $\mathrm{y}=\mathrm{a}+\mathrm{b} *$ $\mathrm{f}+\mathrm{c} * \mathrm{f}^{2} \mathrm{e}$ linear-platô, $\mathrm{y}=\mathrm{a}+\mathrm{b} * \mathrm{f}, \forall \mathrm{f} \leq \mathrm{f} * \mathrm{e} \mathrm{y}=\mathrm{K}$ $\forall \mathrm{f} \geq \mathrm{f}^{*} \operatorname{com} \mathrm{f}^{*}=(\mathrm{k}-\mathrm{a}) / \mathrm{b}$. 


\section{Resultados e Discussão}

Não houve interação entre os níveis de proteína bruta $(\mathrm{PB})$ e fitase em nenhum dos parâmetros de desempenho. Foi observado efeito dos níveis de PB sobre o ganho de peso (GP) $(\mathrm{P} \leq 0,03)$ e a conversão alimentar (CA) ( $\mathrm{P} \leq 0,02)$, sendo os melhores resultados obtidos com o nível de $18 \%$ de PB. (Tabela 3). Constatou-se efeito dos níveis de fitase sobre o GP $(\mathrm{P} \leq 0,03)$, que aumentou de forma linear de acordo com a equação $\mathrm{Y}=478,9+0,04184 \mathrm{X}$, com $\mathrm{R}^{2}=85,4 \%$ (Figura 1$)$, e sobre a $\mathrm{CA}(\mathrm{P} \leq 0,05)$, a qual reduziu de forma linear segundo a equação $\mathrm{Y}=2,30-0,000158 \mathrm{X}, \mathrm{com} \mathrm{R}^{2}=61,2 \%$ (Figura 2). Este melhor efeito da fitase sobre o GP e a CA indica que houve liberação do fósforo fítico e, também, possível maior liberação dos aminoácidos presentes, principalmente, no farelo de soja (SELLE et al., 1996). Os autores aumentaram o substrato (fitato) e

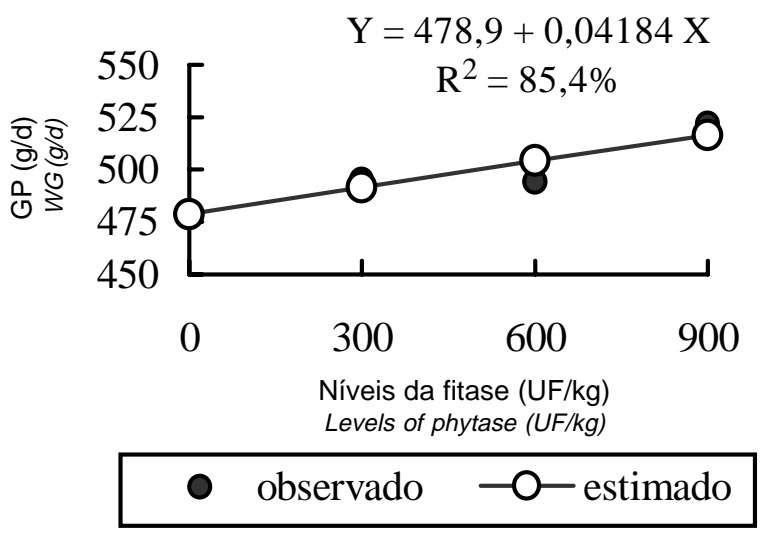

Figura 1 - Efeito dos níveis da fitase nas dietas sobre o GP (g/d).

Figure 1 - Effect of the dietary levels of phytase on the WG(g/d).

Tabela 3 - Médias ajustadas e erro padrão das médias do consumo da dieta (CD - g/ $/ \mathrm{kg}^{0,75} \mathrm{x}$ d), ganho de peso (GP - g/d) e conversão alimentar (CA - g/g) dos animais ${ }^{1}$

Table 3 - Adjusted averages and standard error of the average for daily intake (DI - g/ $\mathrm{kg} \cdot{ }^{75} \mathrm{x} \mathrm{d}$ ), weight gain (WG - g/d) and feed:gain $(\mathrm{g} / \mathrm{g})$ of the animals ${ }^{1}$

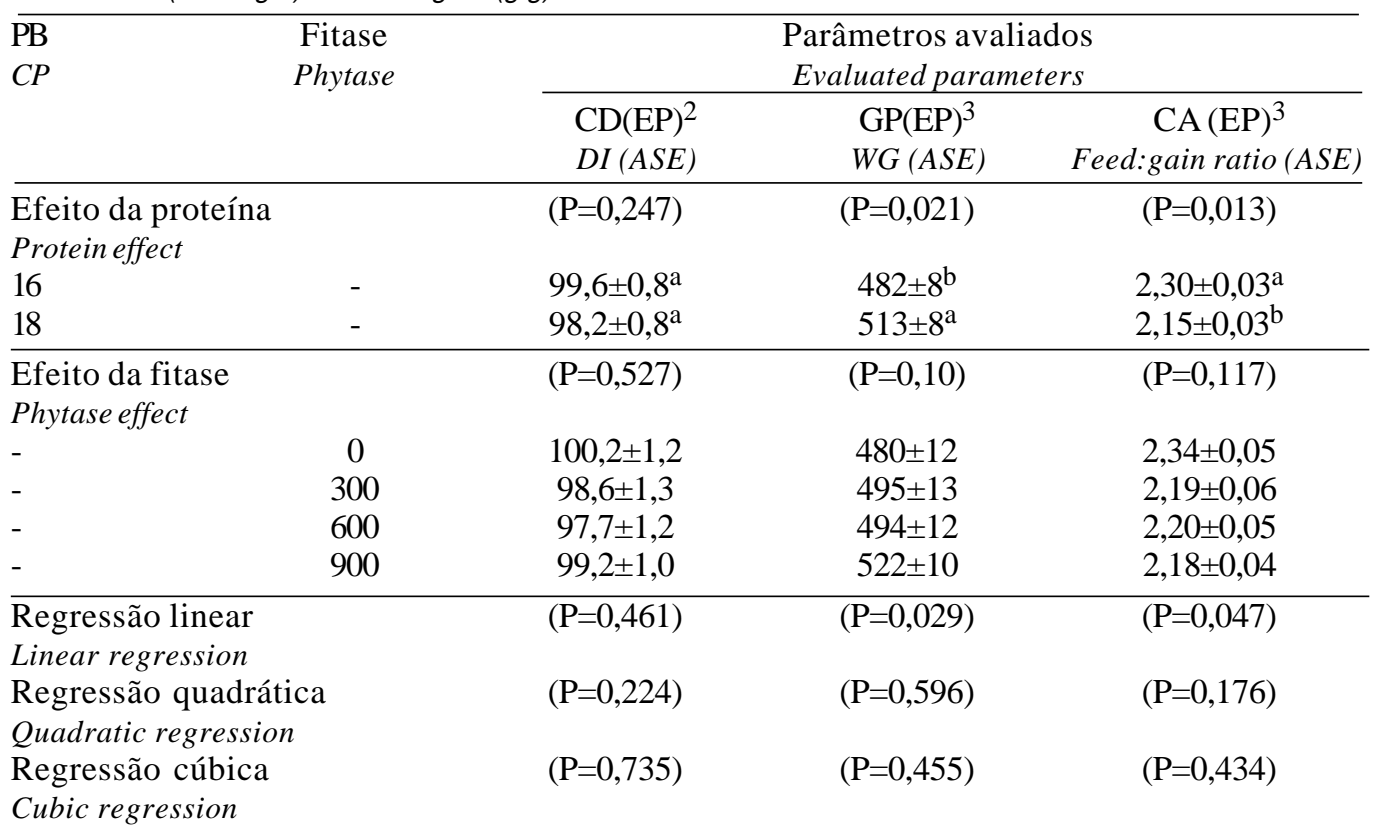

EP - Erro-padrão da média.

1 Não houve interação proteína $x$ fitase $(P>0,10)$, de acordo com o teste $F$.

2 Não houve efeito de proteína $(P>0,10)$ e fitase $(P>0,10)$, de acordo com o teste $F$.

3 Houve efeito de proteína $(P=0,021)$ e fitase $(P \leq 0,12)$.

ASE - Standard error of mean.

1 There was no effect of protein $x$ phytase interaction $(P>.10)$, according to $F$ test.

2 There was no effect of protein $(P>.10)$ and phytase $(P>10)$, according to $F$ test.

3 There was effect of protein $(P=.021)$ and phytase $(P \leq .12)$. 


\section{LÜDKE et al.}

reduziram a relação lisina:energia nas dietas para

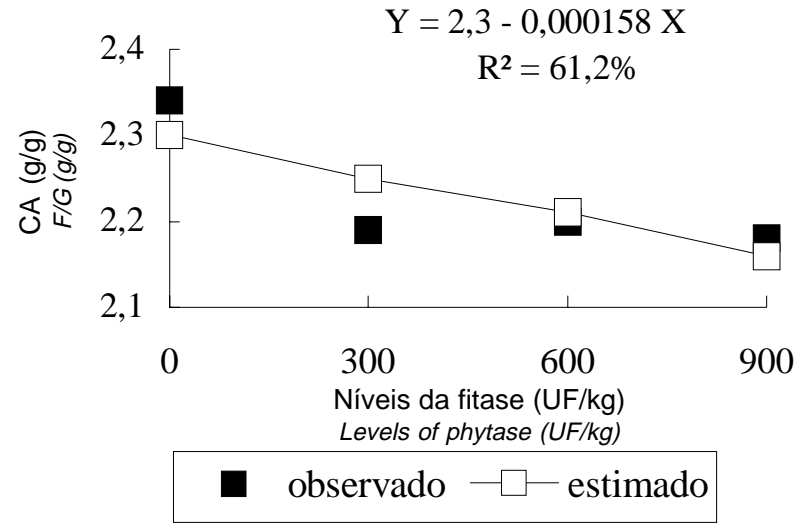

Figura 2 - Efeito dos níveis de fitase nas dietas sobre $\mathrm{CA}(\mathrm{g} / \mathrm{g})$

Figure 2 - Effect in the dietary levels of phytase on the $F / G(g / g)$. leitões. Ao utilizarem fitase (625 UF/ kg da dieta), esses autores observaram aumento na eficiência alimentar e ganho de peso dos animais, mesmo havendo redução do estado protéico da dieta, o que concorda com os resultados obtidos neste trabalho, no qual se constata que, provavelmente, houve liberação dos aminoácidos do complexo fitato-proteína do farelo de soja. BIEHL e BAKER (1996) também observaram aumento no ganho de peso, ao adicionarem $1200 \mathrm{UF} / \mathrm{kg}$ da dieta à base de milho e farelo de soja, com níveis de proteína de acordo com o recomendado $(19,5 \%)$ e abaixo $(15,5 \%)$ deste (sem suplementação de aminoácidos).

Ao ser avaliada a digestibilidade da matéria seca(DMS) (Tabela 4), foi encontrado efeito quadrático $(\mathrm{P} \leq 0,04)$ dos níveis de fitase $(\mathrm{X})$ sobre a DMS (Y), representada pela equação $Y=85,67+0,00495 X-0,00000464 X^{2}$

Tabela 4 - Médias ajustadas e erro padrão da média da digestibilidade da matéria-seca (DMS - \%), digestibilidade do nitrogênio (DN - \%) e retenção do nitrogênio (RN - \%) ${ }^{1}$

Table 4 - Adjusted averages and standard error of the averages for dry matter digestibility (DDM - \%), nitrogen digestibility (ND - \%) and nitrogen retention (NR -\%) ${ }^{1}$

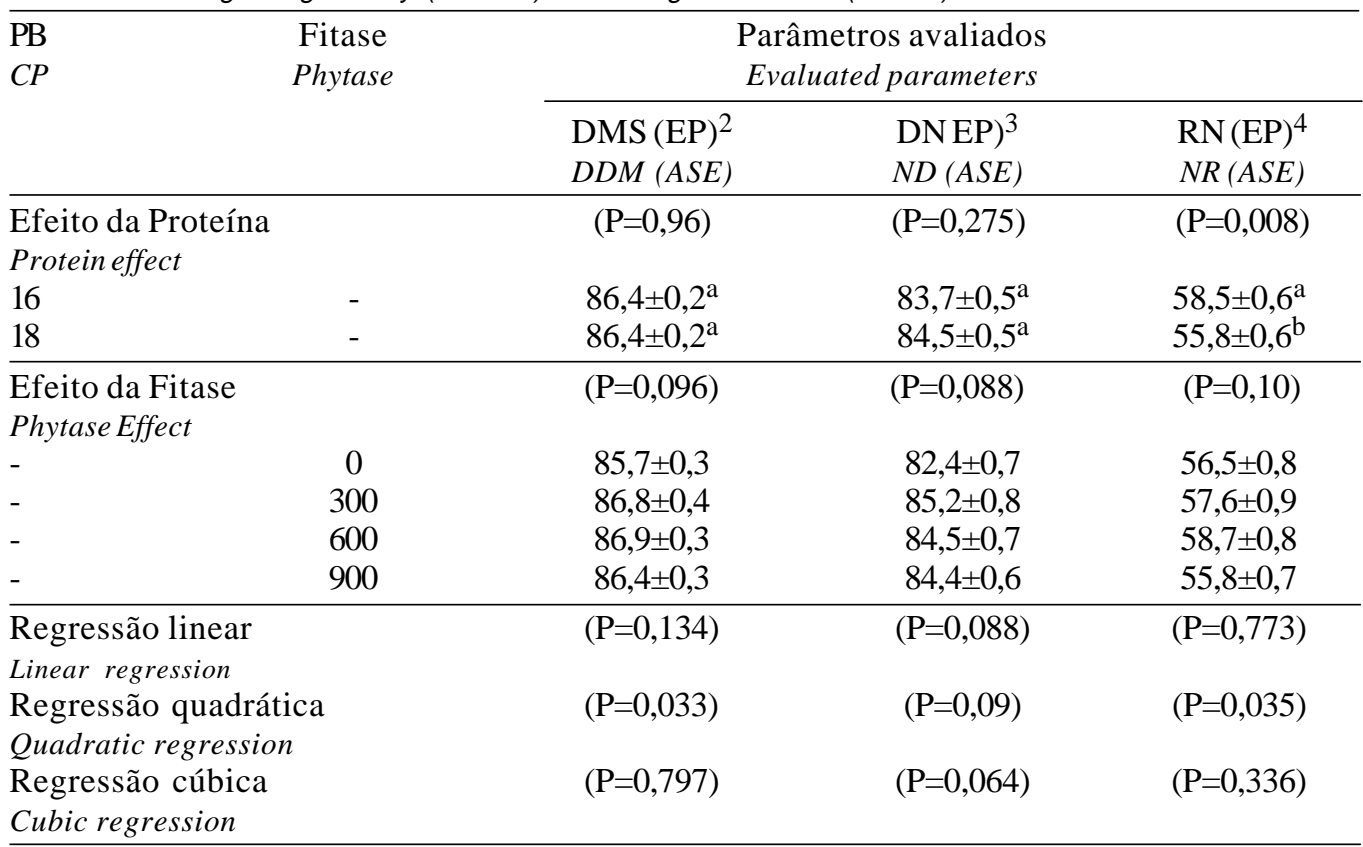

EP - Erro-padrão da média.

1 Não houve interação proteína $x$ fitase $(P>0,10)$, de acordo com o teste $F$.

2 Houve efeito de fitase $(P=0,096)$ de acordo com o teste $F$.

3 Houve efeito de fitase $(P=0,088)$.

4 Houve efeito de proteína $(P=0,008)$ e fitase $(P=0,10)$.

ASE - Standard error of mean.

1 There was no effect of protein $x$ phytase interaction $(P>.10)$, according to $F$ test.

2 There was effect of phytase $(P=.096)$, according to $F$ test.

3 There was effect of phytase $(P=.088)$.

4 There was effect of protein $(P=.008)$ and phytase $(P=.10)$. 
1408 Rev. bras. zootec.

e com $\mathrm{R}^{2}=99,1 \%$, que estimou em $533 \mathrm{UF} / \mathrm{kg}$ o nível de maior DMS (Figura 3). Foi observado que a fitase reduziu, até certo nível de enzima utilizado, a quantidade de material excretado pelos animais, independente da quantidade consumida, pois não houve diferença no consumo dos animais. MROZ et al. (1994) também constataram aumento na DMS de $1,8 \%$, ao adicionarem o nível mais alto de fitase $(800 \mathrm{UF} / \mathrm{kg}$ da dieta) para suínos; no presente experimento, a DMS aumentou em $1,1 \%$ no nível de $600 \mathrm{UF} / \mathrm{kg}$ da dieta. O melhor aproveitamento do nitrogênio foi avaliado por meio da digestibilidade (DN) e retenção do nitrogênio (RN), em que foi encontrado efeito da fitase linear platô e quadrático $(\mathrm{P} \leq 0,04)$, respectivamente (Tabela 4). Como houve efeitos linear e quadrático significativos sobre a $\mathrm{DN}(\mathrm{P} \leq 0,09)$, a equação que melhor se ajustou ao modelo foi a linear platô. As equações foram: $\mathrm{Y}=82,37+0,00933 \mathrm{X}$ para $\mathrm{X} \leq 223$ e $\mathrm{X} \geq 223$, após atingir o platô em $\mathrm{Y}=84,46 \%$, com $\mathrm{R}^{2}=99,9 \%$ (DN) (Figura 4) e $Y=56,28+0,00993 X-0,00001142 X^{2}$, com $\mathrm{R}^{2}=83,9 \%$, sendo que o nível estimado de $435 \mathrm{UF} / \mathrm{kg}$ da dieta foi o que apresentou maior RN (Figura 5). Constatou-se aumento da DN e RN nos animais que consumiram dietas suplementadas com fitase, entre 220 e $435 \mathrm{UF} / \mathrm{kg}$ da dieta. Este fato pode ser atribuído ao aumento da relação $\mathrm{Ca}: \mathrm{P}$ nas dietas com maiores níveis de fitase. Segundo QUIAN et al. (1996), a suplementação de fitase em dietas para suínos deve ocorrer quando esta apresentar relação Ca:P próxima a 1,2:1. Quando a relação molar dos cátions estiver em 2:1 ou 3:1 com o fitato, a formação do complexo insolúvel será maior (OBERLEAS e HARLAND, 1996). O presente experimento apresentou relação $\mathrm{Ca}: \mathrm{P}$ próxima a 2:1 nos últimos níveis de fitase, pois, ao se adicionar a enzima, foi reduzido proporcionalmente o nível de fósforo total, enquanto o teor de cálcio foi o mesmo para todos os níveis de fitase.

Foi encontrada interação proteína $x$ fitase significativa $(\mathrm{P}<0,01)$ sobre os parâmetros de energia, a energia digestível (ED) e energia metabolisável (EM) (Tabela 5). De acordo com a análise de regressão, foi observado efeito linear platô em ambas as variáveis dos níveis de fitase dentro do nível protéico de $16 \%$, em virtude de os efeitos linear $(\mathrm{P} \leq 0,001)$ e quadrático $(\mathrm{P} \leq 0,07)$ terem sido significativos tanto para a $\mathrm{ED}$, quanto para a EM. Com isso, as equações melhores ajustadas foram: $\mathrm{Y}=3883,98+0,48826 \mathrm{X}$ para $\mathrm{X} \leq 296$ e para $X \geq 296$, após atingir o platô em

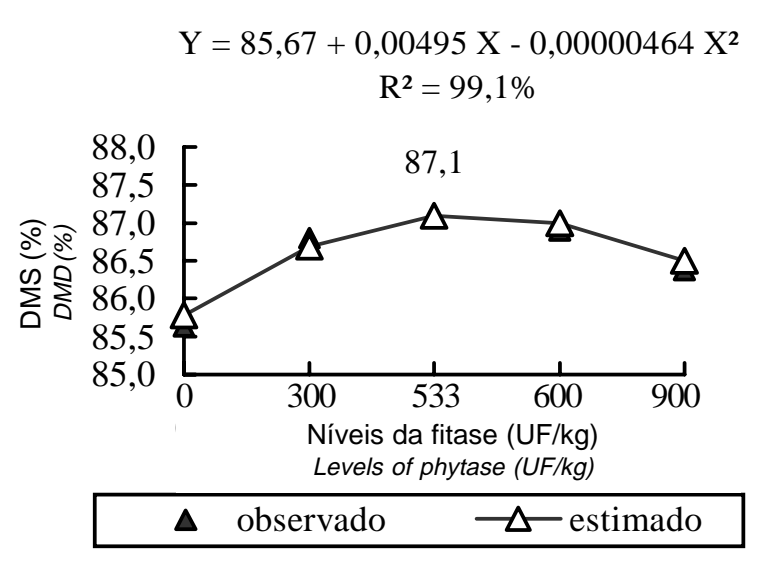

Figura 3 - Efeito dos níveis de fitase nas dietas sobre a DMS (\%). Figure 3 - Effect of dietary levels of phytase on the DMD (\%).

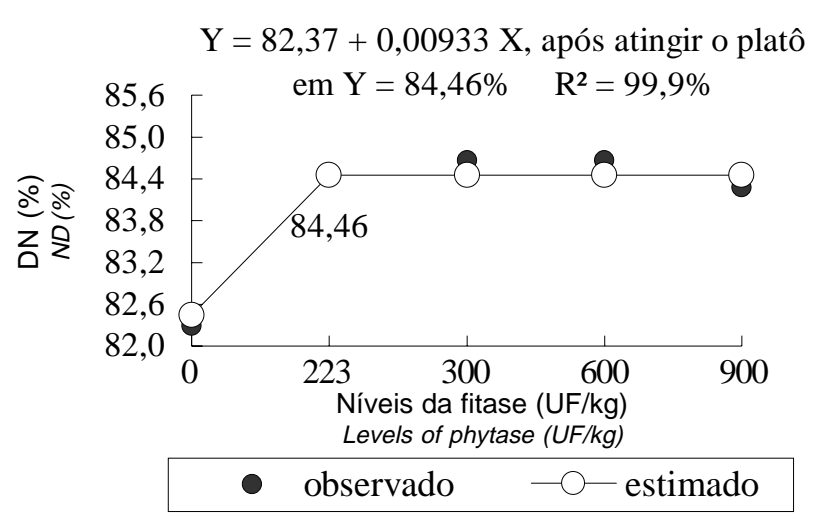

Figura 4 - Efeito dos níveis da fitase nas dietas sobre DN (\%) Figure 4 - Effect of the dietary levels of phytase on the ND (\%).

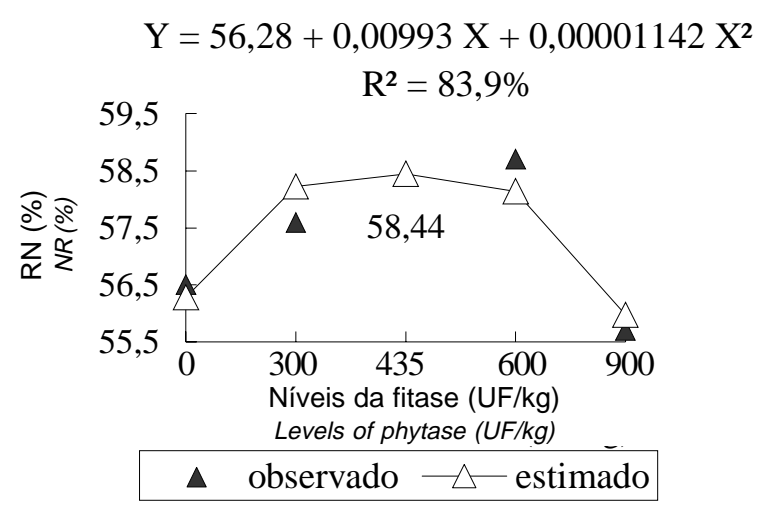

Figura 5 - Efeito dos níveis de fitase nas dietas sobre a RN (\%). Figure 5 - Effect of the dietary levels of phytase on the NR (\%). 
Tabela 5 - Médias ajustadas e erro-padrão da média da energia digestível (ED - $\mathrm{kcal} / \mathrm{kg}$ ) e energia metabolizável (EM - $\mathrm{kcal} / \mathrm{kg})$ dos animais ${ }^{1}$

Table 5 - $\quad$ Adjusted averages and standard error of the digestible energy $(D E-\mathrm{kcal} / \mathrm{kg})$ and metabolizable energy $(M E-\mathrm{kcal} / \mathrm{kg})$ of the animals ${ }^{1}$

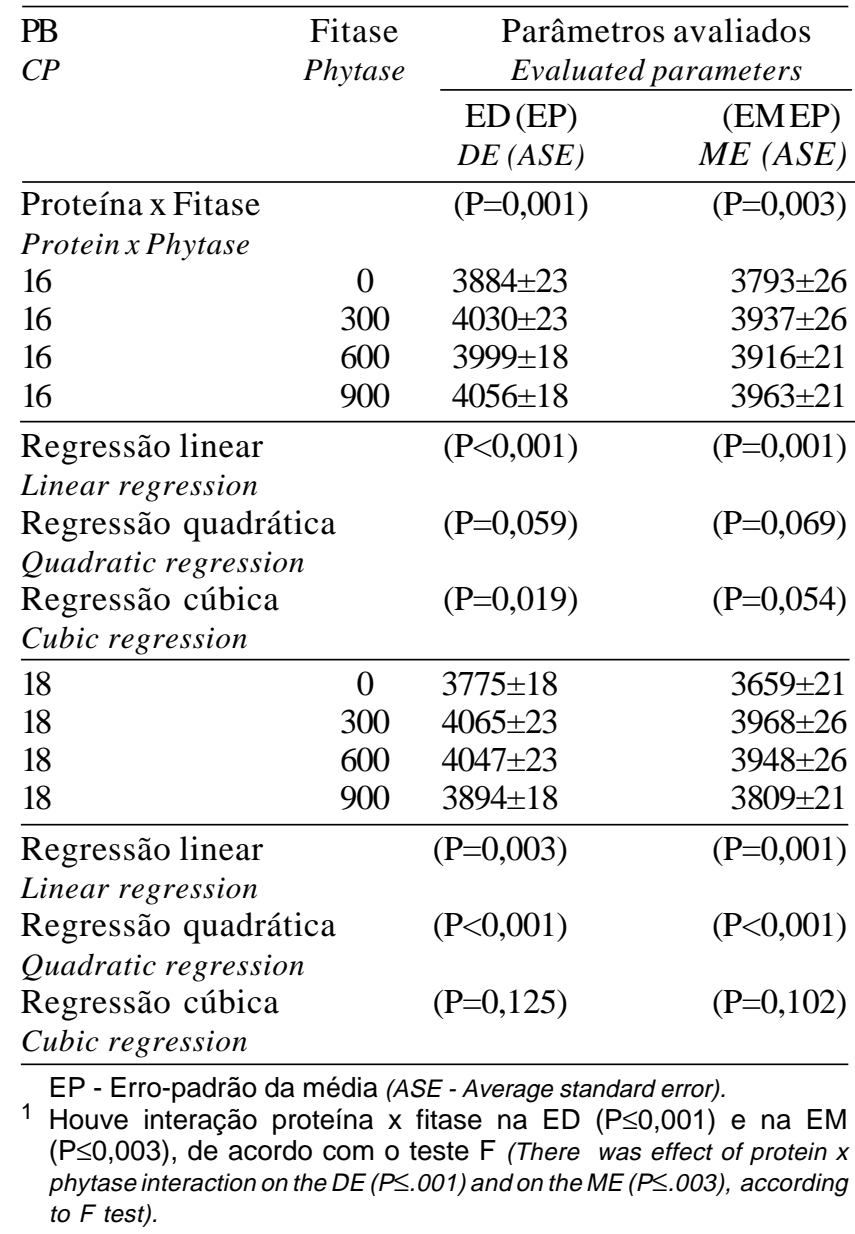

$\mathrm{Y}=4028,46 \mathrm{kcal} / \mathrm{kg}$, com $\mathrm{R}^{2}=91,4 \%$ (ED) e $\mathrm{Y}=3792,88+0,4813 \mathrm{X}$ para $\mathrm{X} \leq 303$ e $\mathrm{X} \geq 303$, após atingir o platô em $\mathrm{Y}=3938,64 \mathrm{kcal} / \mathrm{kg}$, com $\mathrm{R}^{2}=93,9 \%$ (EM). Dentro do nível de $18 \%$ de proteína, houve efeito quadrático $(\mathrm{P}<0,01)$ para as respectivas variáveis, apresentando as seguintes equações: $\mathrm{Y}=3783,46+1,21847 \mathrm{X}-0,000122775 \mathrm{X}^{2}$, com $\mathrm{R}^{2}=97,3 \%$, no qual o nível de fitase com maior ED foi de $496 \mathrm{UF} / \mathrm{kg}$ da dieta, e $\mathrm{Y}=3669,62+1,26446 \mathrm{X}$ - 0,00124577 $X^{2}$, com $R^{2}=96,4 \%$, em que o nível estimado de fitase que acarretou maior EM nos animais foi de $508 \mathrm{UF} / \mathrm{kg}$ da dieta. As equações das variáveis ED e EM estão representadas nas Figuras 6 e 7, respectivamente. Como pode ser observado, a suplementação de fitase em dietas para suínos em crescimento influiu na energia da dieta destes animais. Isto explica a evidência de McKnight (1998),
$\mathrm{Y}=3883,98+0,48826 \mathrm{X} \quad \mathrm{R}^{2}=91,4 \%(16 \% \mathrm{~PB})$

$\mathrm{Y}=3783,46+1,21847 \mathrm{X}-0,000122775 \mathrm{X}^{2}$ $\mathrm{R}^{2}=97,3 \%(18 \% \mathrm{~PB})$

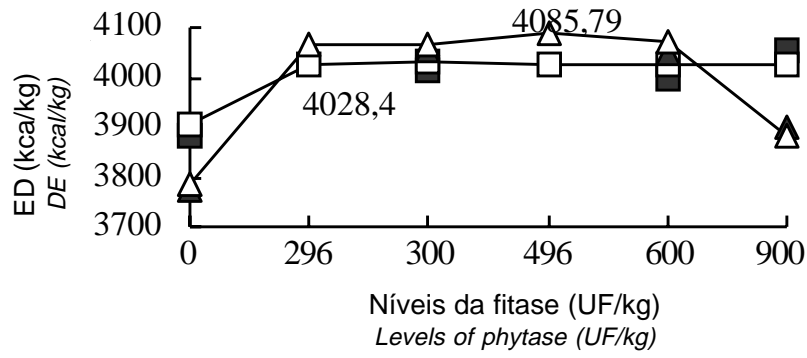

$\square \quad 16 \%$ PB observado $\square-16 \%$ PB estimado

$\triangle 18 \%$ PB observado $\triangle 18 \%$ PB estimado

Figura 6 - Efeito dos níveis da fitase nas nas dietas sobre a $\mathrm{ED}(\mathrm{kcal} / \mathrm{kg})$.

Figure 6 - Effect of the dietary levels of phytase on the DE ( $\mathrm{kcal} / \mathrm{kg})$.

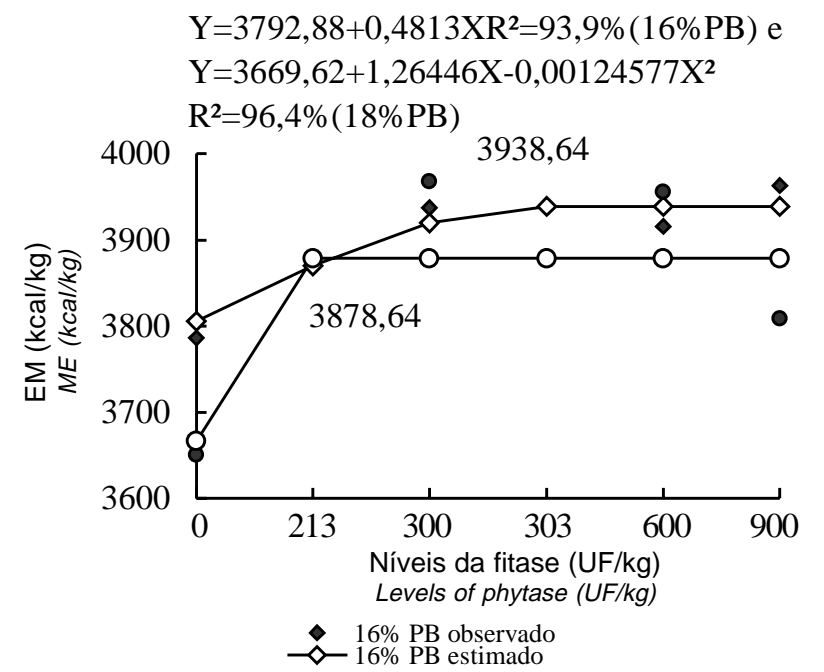

Figura 7 - Efeito dos níveis de fitase dietas sobre a EM ( $\mathrm{kcal} / \mathrm{kg}$ ).

Figure 7 - Effect of the dietary levels of phytase on the ME ( $\mathrm{kcal} / \mathrm{kg})$.

citado por DUDLEY-CASH (1998), o qual afirmou que grande parte dos efeitos do ácido fítico sobre a utilização dos nutrientes estava associada à formação de uma variedade de complexos com o fitato de cálcio, incluindo, neste caso, os ácidos graxos e o amido. No entanto, o efeito máximo da fitase sobre estas variáveis foi de, aproximadamente, $500 \mathrm{UF} / \mathrm{kg}$ da dieta. Este efeito positivo da fitase sobre maior aproveitamento da energia da dieta, além de ter ocorrido também em relação à proteína, explica o aumento linear do GP dos animais com a inclusão da 
1410 Rev. bras. zootec.

Tabela 6 - Médias ajustadas e erro-padrão da digestiblidade do fósforo (DP - \%), retenção do fósforo (RP - \%), digestibilidade do cálcio (DCa - \%) e retenção do cálcio dos animais ( $\mathrm{RCa}-\%)^{1}$

Table 6 - Adjusted averages and standard error of the averages of the phosphorus digestibility (PD - \%), phosphorus retention (PR -\%), calcium digestibility ( $\mathrm{CaD}-\%)$ and calcium retention (CaR) of the animals ${ }^{1}$

\begin{tabular}{|c|c|c|c|c|}
\hline \multirow[t]{2}{*}{$\begin{array}{l}\text { Fitase } \\
\text { Phytase }\end{array}$} & \multicolumn{4}{|c|}{$\begin{array}{c}\text { Parâmetros avaliados } \\
\text { Evaluated parameters }\end{array}$} \\
\hline & $\begin{array}{l}\mathrm{DP}(\mathrm{EP})^{2} \\
P D(A S E)\end{array}$ & $\begin{array}{l}\mathrm{RP}(\mathrm{EP})^{3} \\
P R(A S E)\end{array}$ & $\begin{array}{l}\mathrm{DCa}(\mathrm{EP})^{4} \\
C a D(A S E)\end{array}$ & $\begin{array}{l}\mathrm{RCa}(\mathrm{EP})^{4} \\
C a R(A S E)\end{array}$ \\
\hline Efeito da proteína & $(\mathrm{P}=0,043)$ & $(\mathrm{P}=0,041)$ & $(\mathrm{P}=0,322)$ & $(\mathrm{P}=0,271)$ \\
\hline $\begin{array}{l}\text { Protein effect } \\
16 \\
18\end{array}$ & $\begin{array}{l}59,3 \pm 0,8^{\mathrm{b}} \\
62,0 \pm 0,8^{\mathrm{a}}\end{array}$ & $\begin{array}{l}59,1 \pm 0,8^{\mathrm{b}} \\
61,9 \pm 0,8^{\mathrm{a}}\end{array}$ & $\begin{array}{l}55,0 \pm 2,0^{\mathrm{a}} \\
58,0 \pm 2,0^{\mathrm{a}}\end{array}$ & $\begin{array}{l}51,7 \pm 2,0^{\mathrm{a}} \\
55,0 \pm 2,0^{\mathrm{a}}\end{array}$ \\
\hline $\begin{array}{l}\text { Efeito da fitase } \\
\text { Phytase effect }\end{array}$ & $(\mathrm{P}<0,001)$ & $(\mathrm{P}<0,001)$ & $(\mathrm{P}=0,002)$ & $(\mathrm{P}=0,002)$ \\
\hline $\begin{array}{l}- \\
- \\
- \\
-\end{array}$ & $\begin{array}{l}43,6 \pm 1,2 \\
61,1 \pm 1,4 \\
68,4 \pm 1,2 \\
69,6 \pm 1,0\end{array}$ & $\begin{array}{l}43,4 \pm 1,2 \\
60,9 \pm 1,4 \\
68,3 \pm 1,2 \\
69,5 \pm 1,0\end{array}$ & $\begin{array}{l}43,1 \pm 2,9 \\
57,0 \pm 3,3 \\
64,8 \pm 2,9 \\
61,1 \pm 2,6\end{array}$ & $\begin{array}{l}40,4 \pm 2,9 \\
53,6 \pm 3,3 \\
61,0 \pm 2,9 \\
58,3 \pm 2,6\end{array}$ \\
\hline $\begin{array}{l}\text { Regressão linear } \\
\text { Linear regression }\end{array}$ & $(P<0,001)$ & $(\mathrm{P}<0,001)$ & $(\mathrm{P}=0,001)$ & $(\mathrm{P}=0,001)$ \\
\hline $\begin{array}{l}\text { Regressão quadrática }(\mathrm{P}<0,001) \\
\text { Quadratic regression }\end{array}$ & $(\mathrm{P}<0,001)$ & $(\mathrm{P}=0,014)$ & $(\mathrm{P}=0,02)$ & $(\mathrm{P}=0,02)$ \\
\hline $\begin{array}{l}\text { Regressão cúbica } \\
\text { Cubic regression }\end{array}$ & $(\mathrm{P}=0,468)$ & $(\mathrm{P}=0,50)$ & $(\mathrm{P}=0,711)$ & $(\mathrm{P}=0,763)$ \\
\hline
\end{tabular}

EP - Erro-padrão da média.

1 Não houve interação proteína $x$ fitase $(P>0,10)$, de acordo com o teste $F$.

${ }^{2}$ Houve efeito de proteína $(P=0,043)$ e efeito de fitase $(P<0,001)$, de acordo com o teste $F$ (There was effect of protein [P=.043] and effect of phytase $[P<.001]$ according to $F$ test).

3 Houve efeito de proteína $(P=0,041)$ e fitase $(P<0,001)$, de acordo com o teste $F$.

4 Houve somente efeito de fitase $(P=0,002)$.

ASE - Standard error of mean.

1 There was no effect of protein $x$ phytase interaction $(P>10)$, according to $F$ test.

2 There was effect of phytase $(P=.096)$, according to $F$ test.

3 There was effect of protein $(P=.041)$ and phytase $(P<.001)$, according to $F$ test.

4 There was only effect of phytase $P=.002)$.

enzima. A energia digestível também foi aumentada pela fitase, com efeito quadrático, no trabalho realizado por MURRY et al. (1997), com leitões de aproximadamente $10,9 \mathrm{~kg}$ de peso vivo. Os autores adicionaram nas dietas dos animais níveis de 0,700 e $1000 \mathrm{UF} / \mathrm{kg}$. Todavia, O'QUINN et al. (1997), trabalhando com suínos em terminação, não encontraram efeito da fitase $(0,300$ e $500 \mathrm{UF} / \mathrm{kg}$ da dieta) sobre a digestibilidade da energia em dietas compostas por sorgo e farelo de soja.

Ao serem avaliados os macrominerais, foi verificado efeito de fitase $(\mathrm{P}<0,01)$, independente do nível de proteína da dieta, sobre a digestibilidade do fósforo (DP), retenção do fósforo (RP), digestibilidade do cálcio (DCa) e retenção do cálcio (RCa). Em todas estes parâmetros, como ocorreu efeitos linear e quadrático significativos $(\mathrm{P} \leq 0,02)$, o modelo linear platô foi o que melhor ajustou aos dados, com as respectivas equações: $\mathrm{Y}=43,58+0,05853 \mathrm{X}$ para
$\mathrm{X} \leq 434$ e $\mathrm{X} \geq 434$, após atingir o platô em $\mathrm{Y}=68,97 \%$, com $R^{2}=99,8 \%$ (DP) (Figura 8); $Y=43,41+0,05834 X$ para $X \leq 437$ e $X \geq 437$, após atingir o platô em $\mathrm{Y}=68,89 \%$, com $\mathrm{R}^{2}=99,8 \%$ (RP) (Figura 9); $\mathrm{Y}=44,093+0,00036142 \mathrm{X}$ para $\mathrm{X} \leq 472$ e $\mathrm{X} \geq 472$, após atingir o platô em $\mathrm{Y}=61,15 \%$ com $\mathrm{R}^{2}=97,7 \%(\mathrm{DCa})$ (Figura 10), e $Y=40,433+0,00044022 X$ para $X \leq 436$ e para $X \geq 436$, após atingir o platô em $Y=59,636 \%$ com $\mathrm{R}^{2}=98,5 \%$ (RCa) (Figura 11). Pode ser observado que houve resposta máxima em relação ao efeito da enzima sobre melhor aproveitamento dos macrominerais da dieta, já que foi ajustada uma equação linear platô, na qual a explicação é a mesma da anterior - o aumento na amplitude da relação $\mathrm{Ca}: \mathrm{P}$, ao se elevarem os níveis de fitase. Redução na quantidade de fósforo e cálcio excretado consequentemente, maior digestibilidade - não foi atribuída apenas à redução do consumo destes minerais pela dieta, mas também ao efeito da enzima, pois 


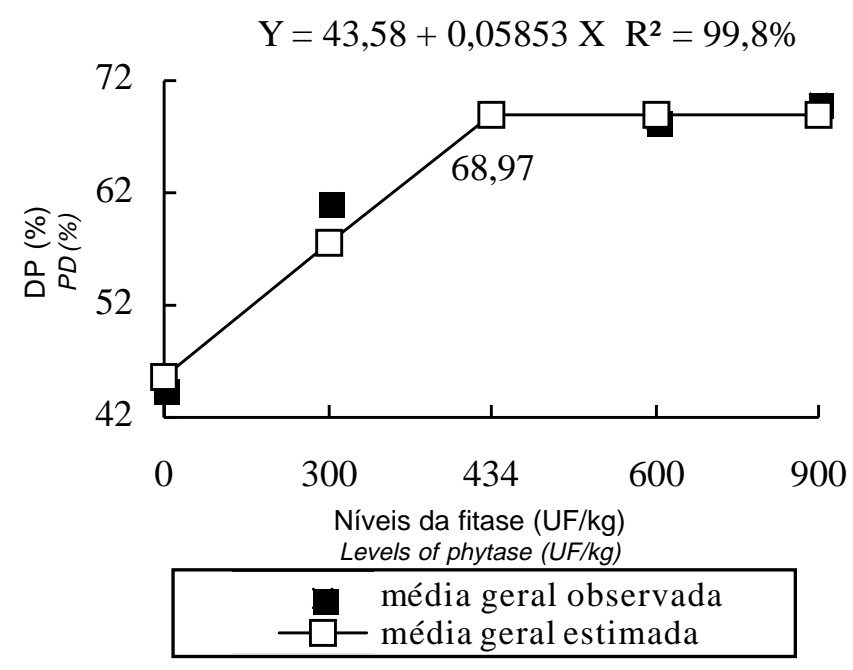

Figura 8 - Efeito dos níveis da fitase nas dietas sobre a DP (\%). Figura 8 - Effect of the dietary levels of phytase on PD (\%).

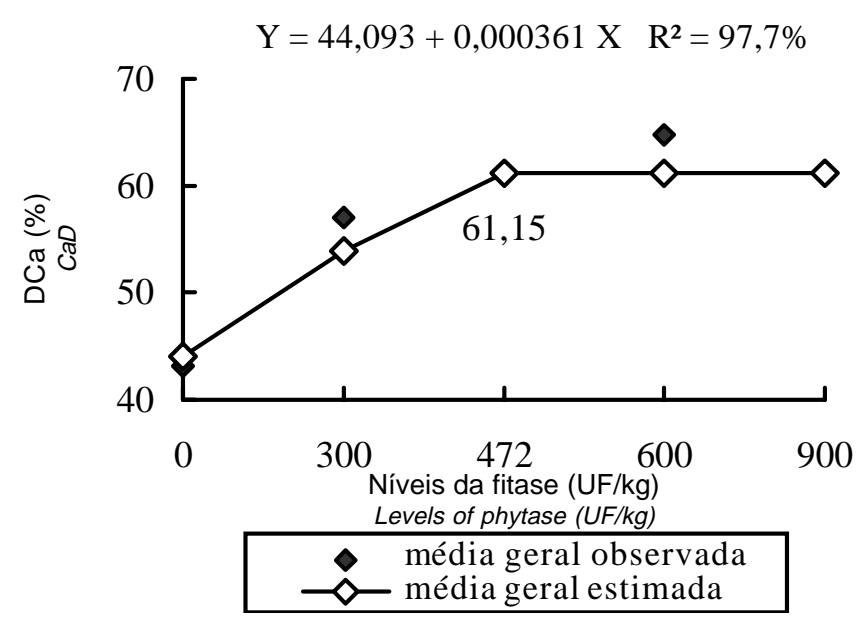

Figura 10 - Efeito dos níveis da fitase nas dietas sobre a DCa $(\%)$.

Figura 10 - Effect of the levels of the phytase in $\mathrm{CaD}(\%)$.

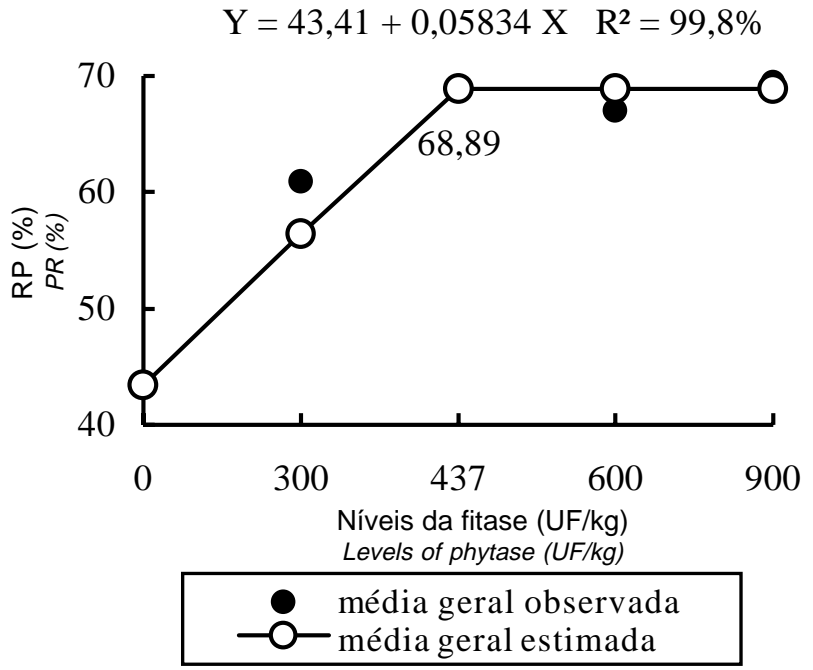

Figura 9 - Efeito dos níveis de fitase nas dietas sobre a RP (\%). Figura 9 - Effect of the dietary levels of phytase on the PR (\%).

$$
\mathrm{Y}=40,433+0,00044022 \mathrm{X} \quad \mathrm{R}^{2}=98,5 \%
$$

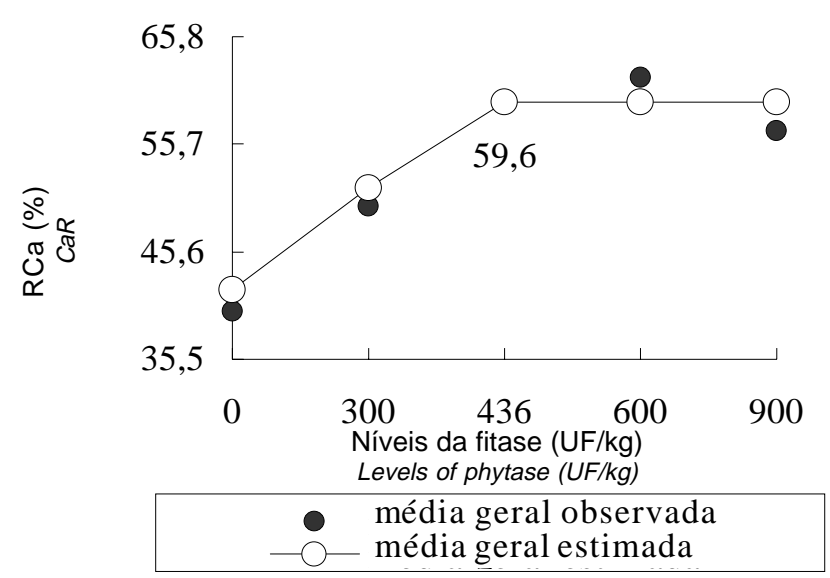

Figura 11- Efeito dos níveis de fitase nas dietas sobre a RCa (\%). Figura 11 - Effect of the dietary levels of phytase on the CaR (\%). 
1412 Rev. bras. zootec.

o desempenho dos animais não foi prejudicado, ao suplementar com fitase. Isto comprova que a enzima acarretou maior aproveitamento de fósforo e cálcio provenientes dos alimentos de origem vegetal das dietas no organismo animal, estando de acordo MROZ et al. (1994), que encontraram redução na excreção destes minerais e, conseqüentemente, aumento na digestibilidade nos suínos em crescimento, quando adicionaram $800 \mathrm{UF} / \mathrm{kg}$ da dieta. LIU et al. (1998) encontraram maior DP, ao adicionarem $500 \mathrm{UF} / \mathrm{kg}$ em dietas, com redução na relação $\mathrm{Ca}: \mathrm{P}$ de 1,5:1 a 1,0:1. No entanto, PALLAUF et al. (1994), utilizaram nas dietas suplementadas com 0,350 e $750 \mathrm{UF} / \mathrm{kg}$ da dieta iguais níveis de cálcio, verificaram que a absorção aparente do fósforo nos leitões na fase inicial aumentou de 54 para $66 \%$ e de 54 para $71 \%$ nos respectivos níveis de fitase adicionados. Além disso, os autores obtiveram também aumento na quantidade de cálcio retido com a adição da enzima. Os resultados deste experimento diferem dos obtidos por BRUCE e SUNDST (1995), que não encontraram variação na DCa nos suínos em crescimento, quando adicionaram 375 e $750 \mathrm{UF} / \mathrm{kg}$ nas dietas destes animais.

\section{Conclusões}

Níveis entre 220 e $508 \mathrm{UF} / \mathrm{kg}$ da dieta foram os que proporcionaram melhor aproveitamento dos nutrientes pelos suínos em crescimento, de acordo com as variáveis de metabolismo estudadas, exceto o desempenho dos animais, que teve melhora linear, abrindo uma oportunidade para que, em experimentos futuros, possam ser acrescentados maiores níveis da enzima.

Houve maior eficiência da enzima, quando adicionada em dietas contendo nível de proteína marginal (16\% de PB), em comparação às dietas com $18 \%$ de proteína, ao se avaliar o aproveitamento de energia pelos animais.

\section{Agradecimento}

À CAPES, pelo suporte financeiro, por intermédio da concessão de bolsas de Pós-Graduação, em nível de Doutorado.

À EMBRAPA - CNPSA de Concórdia - SC, pela oportunidade e condições oferecidas para a realização do trabalho experimental e das análises laboratorais.

\section{Referências Bibliográficas}

ANDERSON, R.L., NELSON, L.A. 1975. A family of models involving intersecting straight lines and concomitant experimental designs useful in evaluating response to fertilizer nutrients. Biometr., 31(1):303-318.

ASSOCIATION OF OFFICIAL ANALYTICAL CHEMISTS AOAC. 1984. Official methods of analysis. Arlington. 1141p.

BIEHL, R.R., BAKER, D.H. 1996. Efficacy of supplemental 1ahydroxicholecalciferol and microbial phytase for young pigs fed phosphorus or aminoacid-deficient corn-soybean meal dietas. J. Anim. Sci., 74(7):2960-2966.

BRUCE, J.A.M., SUNDST, F. 1995. The effect of microbial phytase in diets for pigs on apparent ileal and faecal digestibility, $\mathrm{pH}$ and flow of digesta measurements in growing pigs fed a high-fibre diet. Can.J. Anim. Sci., 75(1):121-127.

CROMWELL, G. L. Application of phosphorus availability data to pratical diet formulation. In: CAROLINS NUTRITION CONFERENCE, 1990, North Caroline. Procedings... North Caroline : Caroline Press, 1990. p.55-57.

CROMWELL, G. L. 1992. Bioavailability of phosphorus in feed ingredients for swine. Pig News Inform., 13(2):75N.

DUDLEY-CASH, W.A. 1998. Phytase may improve more than just availability of phosphorus. Feedstuffs, 70(22):16-46.

CENTRO NACIONAL DE PESQUISA DE SUÍNOS E AVES CNPSA (EMBRAPA). 1984. Tabelas de composição química e valores energéticos de alimentos para suínos e aves. 2.ed. Concórdia. 28p.

JONGBLOED, A.W. 1987. Lelystad Rapport I.V.V.D. 16.ed. London: Rapport I.V.V.D. 343p.

KORNEGAY, E.T., QUIAN, H. 1996. Replacement of inorganic phosphorus by microbial phytase for young pigs fed on a maize-soybean-meal diet. Br. J. Nutr., 76(4):563-578.

LABTEST. 1985. Sistemas diagnósticos Ltda para determinação de fósforo inorgânico "in vitro". Belo Horizonte (Receituário).

LABTEST. 1996. Sistemas Diagnósticos Ltda para determinação do cálcio "in vitro", Lagoa Santa. (Receituário).

LEHNINGER, A.L., NELSON, D.L., COX, M.M. 1993. Principles of biochemistry. 2. ed. New York : Worth Publishers. 1013p.

LIU, J., BOLLINGER, D.W., LEDOUX, D.R. et al. 1998. Lowering the dietary calcium to total phosphorus ratio increases phosphorus utilization in low-phosphorus cornsoybean meal diets supplemental with microbial phytase for growing-finishing pigs. J. Anim. Sci., 76(3):808-813.

MORRIS, E.R. 1986. Phytate and mineral biovailability. In: Graf, E. Phytate Chemistry and Application, Minneapolis: Pilatus. p.57-76.

MrOZ, Z., JONGBLOED, A.W., KEMME, P.A. 1994. Apparent digestibility and retention of nutrients bound to phytate complexes as influenced by microbial phytase and feeding regimen in pigs. J. Anim. Sci., 72(1):126-132.

MURRY, A.C., LEWIS, R.D., AMOS, H.E. 1997. The effect of microbial phytase in a pearl millet-soybean meal diet on apparent digestibility and retention of nutrients, serum mineral concentration and bone mineral density of nursery pigs. J. Anim. Sci., 75(5):1284-1291.

NATIONAL RESEARCH COUNCIL - NRC. 1988. Nutrients requerimentes of swine. 9.ed. Washington, D.C. 90p.

NATIONAL RESEARCH COUNCIL - NRC. 1998. Nutrient requeriments of swine. 10.ed. Washington, D.C. 189p. 
OBERLEAS, D., HARLAND, B.F. 1996. Impact of phytate on nutrient availability. In: COELHO, M.B., KORNEGAY, E.T. (Eds.) Phytase in animal nutrition and waste management, Mount Olive: BASF Corporation. p.77-84.

O'DELL, B.L., DeBOLAND, A. 1976. Complexation of phytate with proteins and cations in corn germ and oilseeds meals, $J$. Agric. Food Chem., 24(4):804-808.

O'QUINN, P.R., KNABE, D.A., GREEG, E.J. 1997. Efficacy of Natuphos in sorghum-based diets of finishing swine. $J$. Anim. Sci., 75(5):1299-1307.

PALLAUF, J., RIMBACH, G., PIPPIG, S. et al. 1994. Effect of phytase supplementation to a phytate-rich diet based on wheat, barley and soya on the biovalaibility of dietary phosphorus, calcium, magnesium, zinc and protein im piglets. Agr. Res., 47(1):39-48.

PEKAS, J.C. 1968. Versatile swine laboratory apparatus for physiologic and metabolic studies. J. Anim. Sci., 27(5):1303-1306.

QUIAN, H., KORNEGAY, E.T., CONNER JR., D.E. 1996. Adverse effects of wide calcium: phosphorus ratios on supplemental phytase . Efficacy for wealing pigs fed two dietary phosphorus levels. J. Anim. Sci., 74(6):1288-1297.
SAS. INSTITUTE INC. SAS 1990. User's guide: Statistic, version 6.4. Cary,. v.2, 1686p.

SELLE, P.H., RAVINDRAN, V., CADOGAN, D.J. et al. The role of microbial phytases in poultry and pig production. In: AUSTRALIAN POULTRY AND FEED CONVENTION, 10, 1996, Melbourne. Proceedings ... Melbourne: APFC, 1996. p.219-224.

STILLBORN, H. 1998. Nutrition influences animal waste output. Feedstuffs, 70(4):20-47.

Recebido em: 08/11/99

Aceito em: 04/04/00 